J. Dairy Sci. 99:6519-6531

http://dx.doi.org/10.3168/jds.2015-10807

(C) American Dairy Science Association ${ }^{\circledR}, 2016$.

\title{
Randomized noninferiority field trial comparing 2 first-generation cephalosporin products at dry off in quarters receiving an internal teat sealant in dairy cows
}

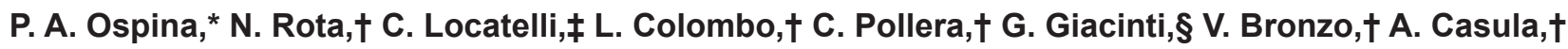

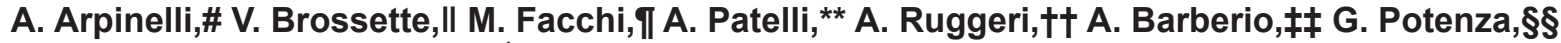 \\ D. V. Nydam, ${ }^{*}$ and P. Moroni ${ }^{*} \dagger^{1}$ \\ *Department of Population Medicine and Diagnostic Sciences, College of Veterinary Medicine, Cornell University, Ithaca, NY 14853 \\ †Dipartimento di Medicina Veterinaria, and \\ ‡Dipartimento di Scienze Veterinarie per la Salute, la Produzione Animale e la Sicurezza Alimentare, Università degli Studi di Milano, \\ via Celoria 10, 20133 Milan, Italy \\ §Istituto Zooprofilattico Sperimentale del Lazio e della Toscana Mario Aleandri, Via Appia Nuova 1411, 00178, Rome, Italy \\ \#Practitioner, via S. Bernadette 31, 00167 Rome, Italy \\ IIPractitioner, via Guido Reni 96/66, 10136 Turin, Italy \\ IIStudio Associato Veterinari Bergamaschi via Verdi 8, 24060 Castelli Calepio, Bergamo, Italy \\ ${ }_{* \star}^{*}$ Embryovet Cascina Bosco 6, 25028 Verolonuova, Brescia, Italy \\ ††Armigio via Donatori di Sangue 36, 25020 San Paolo, Brescia, Italy \\ łłlstituto Zooprofilattico Sperimentale delle Venezie, Sez. Terr. Vicenza, 36100 Vicenza, Italia \\ $\S \S$ Merial Italia SpA, Viale Bodio, 37, 20158 Milan, Italy
}

\section{ABSTRACT}

The study objective was to compare 2 commercial dry cow mastitis products at the quarter level, with concurrent internal teat sealant application, evaluating the cure risk difference, odds of a cure, odds of a new intramammary infection (NIMI) during the dry period, and risk for a clinical mastitis (CM) case between calving and $60 \mathrm{~d}$ in milk (DIM). A total of 590 cows $(2,360$ quarters) from 8 commercial dairy herds in Italy were enrolled and randomized to 1 of the 2 treatments at dry off: Cefovet A (CF; $250 \mathrm{mg}$ of cephazoline; Merial Italia SpA, Milan, Italy), and Cepravin (CP; $250 \mathrm{mg}$ of cephalonium dehydrate MSD Animal Health Srl, Segrate, Italy). Quarter milk samples were collected before dry cow therapy treatment at dry off, 2 to 9 DIM, and 10 to 17 DIM. Quarter milk samples from CM cases were collected during the first 60 DIM. Noninferiority analysis was used to evaluate the effect of treatment on the risk difference of a bacteriological cure during the dry period, the primary outcome. The odds of cure, developing a NIMI during the dry period, and the risk of a CM event within 60 DIM were evaluated with multivariable logistic regression and hazard analysis, respectively. The overall crude quarter-level prevalence

Received December 22, 2015.

Accepted April 25, 2016.

${ }^{1}$ Corresponding author: pm389@cornell.edu of NIMI at dry off was $15.3 \%$. The most common pathogen isolated from milk samples at dry-off was coagulase-negative staphylococci. Noninferiority analysis showed no effect of treatment on the risk difference for a cure between dry off and both postpartum samples, difference was 0.013 . The least squares means from the multivariable model evaluating the odds of cure was $94 \%$ for $\mathrm{CF}$ and $95 \%$ for CP. We observed no effect of treatment on the odds for the presence of a NIMI at 2 to 9 DIM (least squares means: $\mathrm{CF}=0.09$ and $\mathrm{CP}=$ $0.07)$, nor did we note a difference in risk of experiencing a CM event between calving and 60 DIM (hazard ratio $=0.8)$. In conclusion, no difference was observed between the 2 products evaluated when assessing the aforementioned outcomes in quarters also receiving an internal teat sealant.

Key words: dry cow therapy, randomized noninferiority field-trial, first-generation cephalosporin, intramammary infection

\section{INTRODUCTION}

Blanket dry cow therapy (DCT), which refers to the intramammary infusion of all quarters of all cows at dry off with a long-acting antimicrobial, is a procedure recommended by the National Mastitis Council (NMC) as a mastitis-control practice. The DCT is used for curing susceptible existing subclinical infections and for preventing new intramammary infections (NIMI), which could be acquired during the early dry period. This DCT has helped to reduce the NIMI risk from 30 
to $60 \%$ in untreated cows down to 0 to $15 \%$ in treated cows (Halasa et al., 2009) and DCT has also been associated with a decrease in clinical mastitis $(\mathbf{C M})$ cases during lactation (Whist et al., 2006).

Although the majority of NIMI can be subclinical during the dry period, these infections can become clinical in early lactation (Green et al., 2002). It has been estimated that $55 \%$ of environmental infections established early in the dry period, including gramnegative IMI, can persist into the next lactation and can result in CM cases (Todhunter et al., 1995). In fact, $52 \%$ of all clinical coliform mastitis cases occurring in the first 100 DIM of lactation may originate during the previous dry period (Bradley and Green, 2000). Smith et al. (1985) also reported that the risk for NIMI from environmental pathogens can be 10 times higher during the dry period than during lactation.

Several authors have evaluated the efficacy between DCT and their association to both quarter- and cowlevel outcomes during lactation (Arruda et al., 2013a,b; Scherpenzeel et al., 2014; Johnson et al., 2016) in herds in the United States. Although products undergo rigorous testing with a negative control before becoming publically available, no data is available for the Italian market comparing Cefovet A (CF; Merial Italia SpA, Milan, Italy), which contains cephazoline, and Cepravin (CP; MSD Animal Health srl, Segrate, Italy), which contains cephalonium dehydrate. These products are available in Italy and have a significant difference in both milk and meat withhold time, as well as pathogens on the label. There is a $0-\mathrm{h}$ milk withhold after calving if the dry period length is at least $30 \mathrm{~d}$ for CF and 168-h (7 d) withhold with a 51-d dry period for CP. Both products are labeled to reduce the frequency of existing infections and limit new infections with Streptococcus agalactiae, Streptococcus uberis, Streptococcus dysgalactiae, and Staphylococcus aureus; however, CP also includes Actinomyces pyogenes, Corynebacterium ulcerans, Escherichia coli, Proteus spp., Klebsiella spp., Citrobacter spp., and Enterobacter spp.

The objective of the current study was to compare the efficacy of these 2 commercial DCT products in Italian herds in quarters also infused with an internal teat sealant. Efficacy was measured by quarter-level risk difference for cure of an IMI during the dry period, odds of a cure and development of NIMI over the dry period, and risk for experiencing a CM event between calving and 60 DIM. The hypothesis tested was that quarters infused with $\mathrm{CF}$ would have a noninferior proportion (a priori set delta $=0.1$ ) of quarters cured from preexisting IMI, and no difference in the odds of a NIMI postcalving or risk of CM from calving to $60 \mathrm{DIM}$ compared with quarters infused with $\mathrm{CP}$.

\section{MATERIALS AND METHODS}

\section{Study Design and Product Information}

A randomized clinical field trial to evaluate noninferiority between $2 \mathrm{DCT}$ products was conducted from March 2014 to November 2014 in 8 commercial dairy herds $(\mathrm{A}-\mathrm{H})$ in Italy. Cow enrollment began in March and continued until the predetermined sample size was enrolled; cows were then followed forward in time until 60 DIM. Eligible cows were randomly allocated to treat all 4 quarters with 1 of the 2 DCT according to a previously prepared randomized spreadsheet created in Excel software (Microsoft Corp., Redmond, WA). Randomization was blocked within farms. The authors residing at University of Milano and Istituto Zooprofilattico Sperimentale visited the herds weekly and conducted all study enrollment and collected milk samples at the 3 different time points [dry off $(\mathbf{S 1})$, within 2 to 9 DIM (S2), and within 10 to 17 DIM (S3)]. Milk from cows with CM up to 60 DIM was collected by trained on-farm personnel within each herd, with training and supervision conducted by the principal investigators.

Cefovet A contains $250 \mathrm{mg}$ of cephazoline and $85 \mathrm{mg}$ of aluminum distearate in a stable olive oil to reach a weight of $3 \mathrm{~g}$. It is labeled for treatment and prevention of mastitis caused by Strep. agalactiae, Strep. uberis, Strep. dysgalactiae, and Staph. aureus. Milk withholding times are $0 \mathrm{~d}$ after calving if the dry period length is at least $30 \mathrm{~d}$ ( $14 \mathrm{~d}$ if the dry period length is shorter); meat withholding time is $0 \mathrm{~d}$, with the exception of the mammary gland, which cannot be used for human consumption. The second antibiotic, Cepravin, is composed of $250 \mathrm{mg}$ of cephalonium dehydrate, aluminum distearate, and liquid paraffin to reach a weight of 3 g. It is labeled to reduce the frequency of existing infections and prevent new infections caused by Strep. agalactiae, Strep. uberis, Strep. dysgalactiae, Staph. aureus, A. pyogenes, C. ulcerans, E. coli, Proteus spp., Klebsiella spp., Citrobacter spp., and Enterobacter spp. Milk withholding times are $51 \mathrm{~d}$ postinfusion plus 168 $\mathrm{h}(7 \mathrm{~d})$ postcalving, whereas meat withholding time is $2 \mathrm{~d}$.

\section{Herd Selection}

Herds were considered for inclusion in the study if they agreed to comply with the study protocol and had regular DHIA testing. This convenience sample of herds averaged 450 lactating cows (varying from 120 to 1,198), with a 1-yr average bulk tank SCC of 240 $\times 10^{3}$ cells $/ \mathrm{mL}$ (varying from 180 to $350 \times 10^{3}$ cells/ $\mathrm{mL}$ ), and a daily herd milk production average of 32 
FIELD TRIAL OF FIRST-GENERATION CEPHALOSPORIN

Table 1. Herd descriptors for herds from northern (N.) and central Italy in the current study

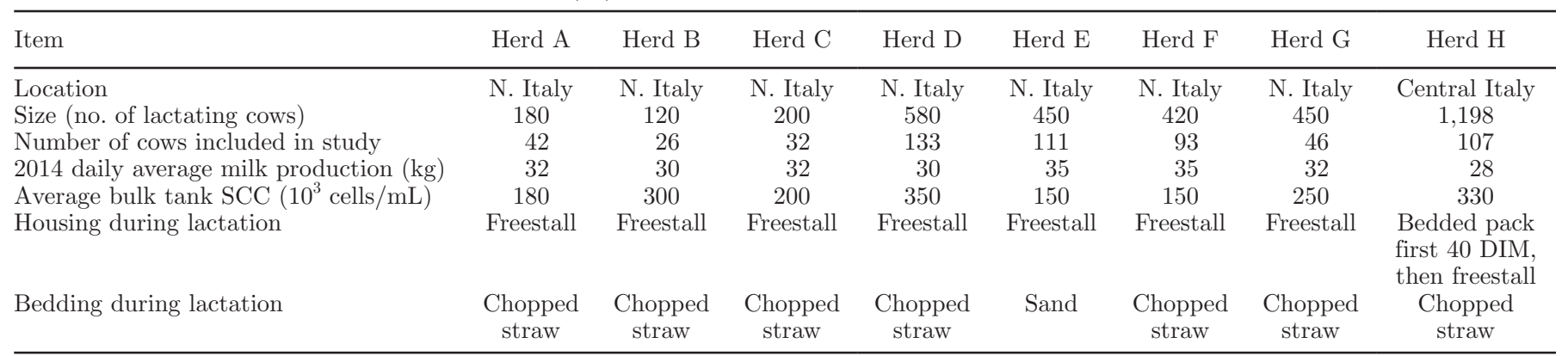

$\mathrm{kg}$ (varying from 28 to $35 \mathrm{~kg}$ ). All herds (Table 1) had freestall housing, with mattresses bedded with chopped straw during the dry period. Herds A to $G$ were located close to the laboratory at Dipartimento di Scienze Veterinarie per la Salute, la Produzione Animale e la Sicurezza Alimentare, and herd $\mathrm{H}$ was close to Istituto Zooprofilattico Sperimentale del Lazio e della Toscana. All herds routinely used an internal teat sealant at dry off and blanket DCT. Orbeseal (Zoetis Italia S.r.l., Latina, Italy), was used in all farms except farm G, which used Intraseal (Norbrook Laboratories Limited, Newry, Northern Ireland). Herds were also prescreened using bulk tank culture to determine that they were negative for Mycoplasma spp.

\section{Cow Enrollment}

Cows eligible for enrollment had no record of receiving parenteral or intramammary treatment with an antibacterial or anti-inflammatory medication during the $30 \mathrm{~d}$ immediately before dry off and showed no signs of $\mathrm{CM}$ at dry off. Cow identification numbers were previously assessed and animals were checked for previous medication.

During the study, DHIA testing was performed monthly on all herds, which evaluated milk production, fat, protein, and SCC. Cow data were collected using a computerized herd record keeping system Afifarm (TDM SRL, San Paolo Brescia, Italy) or with an Excel file.

\section{Sample Collection}

Cows due to be dried off were brought into the parlor for their last milking and routine dry cow protocol. The BCS were evaluated at S1, S2, and S3 by the authors using a 5-point scale (Ferguson et al., 1994). Teat-end scores and cow hygiene scores were evaluated by authors during the 3 visits. Teat-end scores ranged from 1 (no teat end crack or callosity) to 4 (cracked teat end) according to the scale proposed by Falkenberg et al. (2003); udder hygiene scores ranged from 1 (clean) to 4 (dirty) according to the scale presented by Schreiner and Ruegg (2003). The udder and milk were inspected for signs of CM (i.e., redness, heat, swelling, and pain or abnormal color, clots, and abnormal consistency, respectively). Before any milk sample was obtained, teat ends were carefully cleaned and disinfected with chlorhexidine and $70 \%$ alcohol in accordance with NMC (1999) recommendations for aseptic collection of milk samples. First streams of foremilk were discharged, and then approximately $10 \mathrm{~mL}$ of milk was collected with a sterile technique from each teat into sterile vials. These vials were previously identified with herd, cow number, quarter, and date. Samples were transported at $4^{\circ} \mathrm{C}$ to the laboratory and frozen at $-20^{\circ} \mathrm{C}$ until bacteriological assays and SCC tests were performed. The SCC was estimated with an automated somatic cell counter (Bentley Somacount 150, Bentley Instrument, Chaska, $\mathrm{MN})$. The milking took place after the milk sample was collected.

The same procedure was performed for all milk samples obtained (i.e., at S1, S2, and S3) and when samples of $\mathrm{CM}$ cases were collected by farm personnel. The CM samples were frozen $\left(-20^{\circ} \mathrm{C}\right)$ at the farm until the next visit by investigators (routinely within $1 \mathrm{wk}$ ).

Immediately after the final milking, at S1, all 4 quarters were cleaned with gauze soaked in $70 \%$ alcohol and then the assigned treatment was infused into each of the 4 quarters. In accordance with label instructions, the cannula was inserted partially and the antimicrobial preparation was massaged into the gland. Following the label recommendations, an internal teat sealant was infused into the teat cistern. All cows were postdipped and moved into dry cow facilities.

\section{Bacteriological Analysis}

Milk samples were thawed at room temperature. Bacteriological milk culture were performed at the Uni- 
versity of Milano and Istituto Zooprofilattico Sperimentale, which followed published procedures recognized by the NMC for bovine mastitis (NMC, 1999). Laboratory technicians were blinded to treatment and cow. Ten microliters of each milk sample were spread on blood agar plates ( $5 \%$ defibrinated sheep blood). Plates were incubated aerobically at $37^{\circ} \mathrm{C}$ and examined after 24 and $48 \mathrm{~h}$. Colonies were provisionally identified based on size, Gram stain, morphology, and hemolysis pattern. Representative colonies were then subcultured on blood agar plates and incubated again at $37^{\circ} \mathrm{C}$ for 24 $\mathrm{h}$ to obtain pure cultures. Gram-positive cocci found negative to catalase reaction test were identified as streptococci and species were differentiated by further biochemical tests (growth in $6.5 \% \mathrm{NaCl}$ broth, esculin hydrolysis, fermentation of ribose, sorbitol, sucrose, and inulin). Coagulase tube test was used to differentiate catalase-positive, gram-positive cocci as Staph. aureus or CNS. Gram-negative isolates were identified using colony morphology, Gram-staining characteristics, oxidase test, indol test, and inoculation in Simmons citrate (Laboratorios Conda, Madrid, Spain), motility indol ornithine, and biochemical reactions on MacConkey (Oxoid, Basingstoke, UK). Microorganisms other than bacteria were confirmed by microscopic appearance. Samples with the growth of 3 or more pathogens were considered contaminated.

\section{Definition of Infection Status}

Presence of an IMI. An IMI was defined as 1 or more colonies isolated from the $10-\mu \mathrm{L}$ milk sample for all pathogens except for CNS. For CNS, 2 or more colonies isolated from the $10-\mu \mathrm{L}$ milk sample were needed to establish presence of an IMI (Dohoo et al., 2011).

Bacteriological Cure. A cure was defined as not culturing the same pathogen in either the S2 or S3 sample when compared with S1. Quarters that became compromised during the dry period (e.g., blind quarters) or quarters with contaminated or missing samples were not included in the analysis.

Presence of a NIMI. A NIMI was defined as a quarter from which no pathogens were cultured at S1, but growth was detected in the first postpartum sample (S2) or if a different (new) pathogen was recovered in this sample. Based on this definition, it was possible for the same quarter to experience both a cure and a NIMI. Quarters that had contaminated samples were not included in the NIMI analysis.

CM. A CM event was defined as having abnormal milk or abnormal quarter or systemic illness identified by farm personnel. A quarter experiencing more than 1 case of CM within 60 DIM was counted once.

\section{Statistical Analysis}

To estimate the sample size, the primary outcome was considered risk for a cure between S1 and both S2 and S3 (i.e., the quarter would have to have an infection at dry off to be included at being at risk of cure). The results of the S2 and S3 tests were evaluated in parallel (i.e., a positive at either S2 or S3 would be counted as a positive test result culture, hence not a cure) to increase the sensitivity of the test. The minimum difference in cure rate to declare noninferiority of CF compared with CP was 10\% (i.e., the delta for an important difference was $10 \%)$. To demonstrate noninferiority, 275 infected quarters at $\mathrm{S} 1$ were needed in each group assuming $\alpha=0.05, \beta=0.1$, and $80 \%$ success in the reference group (Blackwelder and Chang, 1984). Assuming 30\% prevalence of infections at S1 and 10\% loss to followup, a minimum of 255 cows per group (1,019 quarters per group) would need to be enrolled.

All statistical analyses were conducted using SAS (version 9.3, SAS Institute Inc., Cary, NC). Initially, descriptive statistics and plots were generated for exploratory data analysis. Basic diagnostic techniques were used to evaluate normality and presence of outliers for continuous data. Characteristics of cows and quarters assigned to the 2 treatment groups were compared at dry off in univariate analysis using the PROC FREQ (chi-squared test) for categorical variables and PROC TTEST for continuous variables. The crude prevalence of IMI were evaluated using the pivot table function in Excel software.

Noninferiority analysis of the effect of treatment on the risk difference for bacteriological cure was completed by comparing the risk difference to a noninferiority margin with the Farrington-Manning Method (Miettinen and Nurminen, 1985; Farrington and Manning, 1990) using PROC FREQ (Schuirmann, 1999; Dann and Koch, 2008). Additionally, the effect of treatment on the odds of cure and NIMI were evaluated using PROC GLIMMIX, with herd and cow included as a random effect to account for clustering effects of quarters within cows and cows within herds. The covariates offered to the model were: DCT (CP or $\mathrm{CF}$ ), parity group (2 levels; lactation $=2$ vs. $>2$ ), linear score at dry off, previous lactation total milk $(\mathrm{kg})$, dry period length (2 levels; $>60$ d vs. $<60$ d), BCS at S1 (2 levels; $\leq 3.0$ vs. $>3.0$ ), teat-end score at S1 (2 levels; 1 and $2=$ 1 vs. 3 and $4=2$ ), hygiene score at S1 (2 levels; 1 and $2=1$ vs. 3 and $4=2$ ). Backward stepwise selection was used; covariates with $P>0.1$ were removed to arrive at the most parsimonious model with treatment group forced into the model. First-order, biologically relevant interactions between the treatment group and 
Table 2. Comparison of cow- and quarter-level parameters at enrollment between treatment groups

\begin{tabular}{|c|c|c|c|}
\hline Variable & \multicolumn{2}{|c|}{ Treatment $^{1}$} & $P$-value ${ }^{2}$ \\
\hline Number of cows & 299 & 291 & - \\
\hline Number of quarters available for analysis & 1,164 & 1,136 & - \\
\hline Number of second-lactation cows & 229 & 230 & 0.5 \\
\hline Number of cows with udder hygiene score 1 and 2 at dry off & 261 & 249 & 0.5 \\
\hline Number of cows with BCS at dry off $\leq 3$ & 47 & 37 & 0.3 \\
\hline Total quarters with an IMI at dry off ( $\%$ of quarters in treatment group) & $185(15.9)$ & $166(14.6)$ & 0.4 \\
\hline Mean milk production $(\mathrm{kg})$ in previous lactation $(95 \% \mathrm{CI})$ & $\begin{array}{l}11,147 \\
(10.721-11.578)\end{array}$ & $\begin{array}{l}10,920 \\
(10.528-11.312)\end{array}$ & 0.2 \\
\hline Mean number of days dry (95\% CI) & $70(67-74)$ & $67(64-69)$ & 0.1 \\
\hline
\end{tabular}

${ }^{1} \mathrm{CF}=$ Cefovet $(250 \mathrm{mg}$ of cephazoline; Merial Italia SpA, Milano, Italy); CP = Cepravin (250 mg of cephalonium dehydrate MSD Animal Health Srl, Segrate, Italy).

${ }^{2}$ When comparing continuous variables, a Student's $t$-test was used and a chi-squared test was used when comparing dichotomous variables.

remaining covariates were tested and remained in the final model if significant $(P<0.05)$.

The effect of DCT group on the risk of a case of CM between calving and 60 DIM was evaluated with Cox proportional hazards regression (PROC PHREG). Clustering at the herd level was controlled for with a COVSANDWHICH statement. The failure date was defined as the date when a quarter had CM. Those quarters that did not experience a $\mathrm{CM}$ event by 60 DIM, or the quarters from cows that were culled or dead $\leq 60$ DIM were right censored. The covariates included in the model were DCT (CP or $\mathrm{CF}$ ), parity group (2 levels; lactation $=2$ vs. lactation $>2)$, linear score $(2$ levels $\leq 4$ vs. $>4$ ) at $\mathrm{S} 1, \mathrm{~S} 2$, and $\mathrm{S} 3$, previous lactation total milk (kg), dry period length (2 levels; $\geq 60$ vs. $<60$ d), and hygiene score (2 levels; 1 and $2=1$ vs. 3 and $4=2$ ) at S1, S2, and S3. Backward stepwise selection was used; covariates with $P>0.2$ were removed to arrive at the most parsimonious model with treatment group forced into the model. First-order, biologically relevant interactions between the treatment group and remaining covariates were tested and remained in the model if significant $(P<0.05)$.

\section{RESULTS}

A total of 2,360 quarters (590 cows; 299 in CF, 291 in CP) were enrolled in the study between March and July 2014 and all cows were followed until 60 DIM (followup ended in November 2014). Of those, 1,196 and 1,164 quarters were allocated to treatment groups $\mathrm{CF}$ and $\mathrm{CP}$, respectively. Eight cows were lost to follow-up during the dry period in the $\mathrm{CF}$ group and 7 cows in $\mathrm{CP}$; therefore, only 1,164 and 1,136 quarters (total of 2,300) were available for analysis in the $\mathrm{CF}$ and $\mathrm{CP}$ treatment groups, respectively. The treatment groups did not differ at enrollment regarding cow-level parameters (Table $2)$.

\section{Prevalence of IMI}

A total of 2,300 quarters were evaluated $(1,164$ in the CF group and 1,136 in the CP group). The overall crude prevalence of IMI at dry off was $15.3 \%$ (Table 3 ) and was not different between treatments $(P=0.4$; Table 2). Table 4 describes the crude frequency of culture results at S1 to S3. The most common pathogen isolated from all time points was CNS (for both treatment groups $70.3,4.9$, and $9.4 \%$ for S1, S2, and S3, respectively). Followed by gram-negative infections (for both treatment groups $9.5,1.2$, and $1.4 \%$ for S1, S2, and $\mathrm{S} 3$, respectively).

\section{Noninferiority Analysis and the Effect of Treatment}

A total of 347 quarters (182 in CF group and 165 in CP group) had an IMI present at S1 and were at risk for cure (Table 5). Overall, the crude proportion of quarters that experienced a cure were 89 and $90 \%$ in CF and $\mathrm{CP}$, respectively. Noninferiority analysis showed no risk difference in cure between the treatment groups; the proportion difference was 0.013 , the a priori set limit was 0.1 . The $95 \% \mathrm{CI}$ for proportion difference was -0.05 to $0.08(P<0.001)$. The interpretation of these results is that the null hypothesis that $\mathrm{CF}$ is inferior to $\mathrm{CP}$ is rejected (Figure 1). 
The final multivariable analysis (Table 6) was limited to DCT which was forced into the model $(P=0.6)$ and teat score at $\mathrm{S} 1(P=0.04)$. The least squares means for the treatment groups in this model were 0.94 (95\% CI: 0.87-0.97) for CF and 0.95 (95\% CI: 0.89-0.98) for CP. Quarters with lower teat-end scores had lower odds of experiencing a cure.

\section{Effect of Treatment on Odds for Experiencing a NIMI at S2}

Table 7 represents the crude quarter-level NIMI between S1 and S2. Quarters with no growth at S1 and growth at $\mathrm{S} 2$, or a different pathogen at S2 when compared with S1, were included in the table and analysis. The overall crude proportion of eligible quarters developing a NIMI was $7 \%$. The most common pathogen isolated was CNS; the average between both treatment groups was $57 \%$. The second most common pathogen isolated was $E$. coli; the average between both treatment groups was $10 \%$. Table 8 represents the multivariable model comparing the odds of experiencing a NIMI between treatment groups and relevant covariates. We noted no difference between treatment groups $(P=$ 0.2 ), and the only covariates retained in the model were length of dry period $(P=0.09)$, teat-end score at S1 $(P=0.02)$, and hygiene score at S2 (0.02). The least squares means for the treatment groups based on this model were 0.09 (0.06 to 0.12 ) and 0.07 (0.05 to 0.09 ) for $\mathrm{CF}$ and $\mathrm{CP}$, respectively. The odds ratio associated with the length of dry period was 1.0 (95\% CI: 0.9-1.0), which indicates a very small, biologically insignificant change; quarters with lower teat-end scores had lower odds of developing a NIMI and cows with lower hygiene scores had larger odds of developing a NIMI.

\section{Effect of Treatment on Risk of CM Between Calving and 60 DIM}

Table 9 represents the crude culture results for CM cases at the cow level. The crude proportion of $\mathrm{CM}$ events was $3.4 \%$ at the quarter level. The most common pathogen isolated was E. coli ( $18 \%$ overall; $11 \%$ in $\mathrm{CF}, 24 \%$ in CP); however, the most common culture result was no growth (23\% overall; $25 \%$ in CF, $21 \%$ in $\mathrm{CP}$ ). The Cox proportional hazards model (Table 10) was used for the analysis of the risk of a CM case at the quarter level. We found no significant difference between treatment groups $(P=0.09)$; however, a numerical difference in mastitis cases was noted, lower in $\mathrm{CF}$. The covariates included in the final model were hygiene at S1 and S2, linear score at S1, length of dry period, and teat-end score at S1 and S2. Animals with lower hygiene scores at $\mathrm{S} 1(P=0.003)$ and $\mathrm{S} 2(P=0.1)$ and teat-end scores at $\mathrm{S} 1(P=0.001)$ were less likely to get mastitis. However, an inverse relationship was seen with linear score at S1 $(P=0.001)$ and teat-end scores at S2 $(P=0.03)$, those with lower scores were more likely to get mastitis; although significantly associated with the outcome $(P=0.01)$, length of dry period was not biologically significant (odds ratio $=1.0$ ).

\section{DISCUSSION}

There was no significant difference between CF and $\mathrm{CP}$ in quarters also treated with a teat sealant in cure risk difference or odds of a cure. Cure was defined as no growth of the organism present at S1 compared with both the S2 and S3 samples in this noninferiority field trial. Additionally, no significant difference was noted when the odds of NIMI at S2, or the risk of CM

Table 3. Crude prevalence (no., with percentages in parentheses ${ }^{1}$ ) of IMI for quarters at $\mathrm{S} 1, \mathrm{~S} 2$, and $\mathrm{S} 3^{2}$ by treatment group ${ }^{3}$ and overall

\begin{tabular}{|c|c|c|c|c|c|c|c|c|c|}
\hline \multirow[b]{2}{*}{ Item } & \multicolumn{3}{|c|}{ Dry off (S1) } & \multicolumn{3}{|c|}{2 to 9 DIM (S2) } & \multicolumn{2}{|c|}{10 to 17 DIM (S3) } & \multirow[b]{2}{*}{ Total } \\
\hline & $\mathrm{CF}$ & $\mathrm{CP}$ & Total & $\mathrm{CF}$ & $\mathrm{CP}$ & Total & $\mathrm{CF}$ & $\mathrm{CP}$ & \\
\hline No growth & $\begin{array}{l}946 \\
(81)\end{array}$ & $\begin{array}{l}940 \\
(83)\end{array}$ & $\begin{array}{r}1,886 \\
(82)\end{array}$ & $\begin{array}{r}1,042 \\
(90)\end{array}$ & $\begin{array}{r}1,043 \\
(92)\end{array}$ & $\begin{array}{r}2,085 \\
(91)\end{array}$ & $\begin{array}{l}984 \\
(85)\end{array}$ & $\begin{array}{r}1,019 \\
(90)\end{array}$ & $\begin{array}{r}2,003 \\
(88)\end{array}$ \\
\hline Contaminated & $\begin{array}{l}20 \\
(2)\end{array}$ & $\begin{array}{l}16 \\
(1)\end{array}$ & $\begin{array}{l}36 \\
(2)\end{array}$ & $\begin{array}{c}8 \\
(1)\end{array}$ & $\begin{array}{c}4 \\
(0.4)\end{array}$ & $\begin{array}{l}12 \\
(0.5)\end{array}$ & $\begin{array}{c}4 \\
(0.3)\end{array}$ & $\begin{array}{c}1 \\
(0.1)\end{array}$ & $\begin{array}{c}5 \\
(0.2)\end{array}$ \\
\hline Blind quarters & $\begin{array}{l}13 \\
(1)\end{array}$ & $\begin{array}{l}14 \\
(1)\end{array}$ & $\begin{array}{l}27 \\
(1)\end{array}$ & $\begin{array}{l}11 \\
(1)\end{array}$ & $\begin{array}{l}13 \\
(1)\end{array}$ & $\begin{array}{l}24 \\
(1)\end{array}$ & $\begin{array}{l}11 \\
(1)\end{array}$ & $\begin{array}{l}15 \\
(1)\end{array}$ & $\begin{array}{l}26 \\
(1)\end{array}$ \\
\hline Total IMI & $\begin{array}{l}185 \\
(16)\end{array}$ & $\begin{array}{l}166 \\
(15)\end{array}$ & $\begin{array}{l}351 \\
(15)\end{array}$ & $\begin{array}{r}103 \\
(9)\end{array}$ & $\begin{array}{l}76 \\
(7)\end{array}$ & $\begin{array}{r}179 \\
(8)\end{array}$ & $\begin{array}{l}153 \\
(13)\end{array}$ & $\begin{array}{l}97 \\
(9)\end{array}$ & $\begin{array}{l}250 \\
(11)\end{array}$ \\
\hline Total quarters & 1,164 & 1,136 & 2,300 & 1,164 & 1,136 & 2,300 & 1,152 & 1,132 & 2,284 \\
\hline Missing culture & $\begin{array}{c}0 \\
(0)\end{array}$ & $\begin{array}{c}0 \\
(0)\end{array}$ & $\begin{array}{c}0 \\
(0)\end{array}$ & $\begin{array}{c}0 \\
(0)\end{array}$ & $\begin{array}{c}0 \\
(0)\end{array}$ & $\begin{array}{c}0 \\
(0)\end{array}$ & $\begin{array}{l}12 \\
(1)\end{array}$ & $\begin{array}{c}4 \\
(0.3)\end{array}$ & $\begin{array}{l}16 \\
(0.7)\end{array}$ \\
\hline
\end{tabular}

${ }^{1}$ Denominator $=$ total quarters, \% rounded up to nearest whole number.

${ }^{2} \mathrm{~S} 1=$ dry-off, $\mathrm{S} 2=2$ to 9 DIM, S3 = 10 to 17 DIM.

${ }^{3} \mathrm{CF}=$ Cefovet (250 mg of cephazoline; Merial Italia SpA, Milano, Italy); CP = Cepravin (250 mg of cephalonium dehydrate MSD Animal Health Srl, Segrate, Italy). 
Table 4. Frequency of bacterial species for quarters at risk for a cure (i.e., quarters with an infection at dry off) by treatment group ${ }^{1}$

\begin{tabular}{|c|c|c|c|c|c|c|c|c|c|}
\hline \multirow[b]{2}{*}{ Bacteria } & \multicolumn{3}{|c|}{ Culture results at $\mathrm{S} 1^{3}$} & \multicolumn{3}{|c|}{ Culture results at $\mathrm{S} 2^{3}$} & \multicolumn{3}{|c|}{ Culture results at $\mathrm{S} 3^{3}$} \\
\hline & $\mathrm{CF}$ & $\mathrm{CP}$ & Total & $\mathrm{CF}$ & $\mathrm{CP}$ & Total & $\mathrm{CF}$ & $\mathrm{CP}$ & Total \\
\hline \multicolumn{10}{|l|}{ Gram-positive } \\
\hline CNS & 112 & 108 & 220 & 10 & 7 & 17 & 23 & 9 & 32 \\
\hline Staphylococcus aureus & 6 & 3 & 9 & 0 & 0 & 0 & 1 & 1 & 2 \\
\hline Streptococcus uberis & 12 & 11 & 23 & 0 & 0 & 0 & 1 & 2 & 3 \\
\hline Streptococcus dysgalactiae & 3 & 7 & 10 & 0 & 0 & 0 & 1 & 0 & 1 \\
\hline Streptococcus spp. & 14 & 6 & 20 & 1 & 0 & 1 & 0 & 0 & 0 \\
\hline Enterococcus faecalis & 5 & 2 & 7 & 0 & 0 & 0 & 1 & 1 & 2 \\
\hline Aerococcus viridans & 1 & 2 & 3 & 0 & 0 & 0 & 0 & 0 & 0 \\
\hline Bacillus spp. & 2 & 3 & 5 & 1 & 0 & 1 & 0 & 1 & 1 \\
\hline Corynebacterium spp. & 9 & 7 & 16 & 0 & 0 & 0 & 0 & 0 & 0 \\
\hline Total gram-positive $(\%)^{2}$ & $164(90.1)$ & $149(90.3)$ & $313(90.2)$ & $12(6.5)$ & $7(4.2)$ & $19(5.5)$ & $27(15.2)$ & $14(8.5)$ & $41(12.0)$ \\
\hline \multicolumn{10}{|l|}{ Gram-negative } \\
\hline Escherichia coli & 16 & 12 & 28 & 1 & 0 & 1 & 1 & 1 & 2 \\
\hline Enterobacter spp. & 2 & 1 & 3 & 0 & 0 & 0 & 0 & 0 & 0 \\
\hline Klebsiella spp. & 0 & 0 & 0 & 0 & 0 & 0 & 0 & 0 & 0 \\
\hline Serratia spp. & 0 & 3 & 3 & 1 & 2 & 3 & 0 & 2 & 2 \\
\hline Other gram-negative & 0 & 0 & 0 & 0 & 0 & 0 & 0 & 0 & 0 \\
\hline Total gram-negative $(\%)^{2}$ & $18(9.9)$ & $15(9.1)$ & $33(9.5)$ & $2(1.2)$ & $2(1.3)$ & $4(1.2)$ & $1(0.7)$ & $3(2.0)$ & $4(1.4)$ \\
\hline Yeast & 0 & 0 & 0 & 0 & 0 & 0 & 0 & 1 & 1 \\
\hline No growth $(\%)^{2}$ & - & - & - & $168(92.3)$ & $156(94.5)$ & $324(93.3)$ & $150(84.3)$ & $146(89.0)$ & $296(86.5)$ \\
\hline Total cultures & 182 & 165 & 347 & 182 & 165 & 347 & 178 & 164 & 342 \\
\hline
\end{tabular}

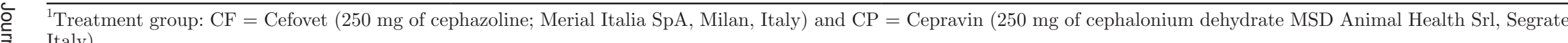
Italy).

D Denominator $=$ total cultures.

$\stackrel{\rightarrow}{\circ}{ }^{3} \mathrm{~S} 1=$ dry-off, S2 = 2-9 DIM, S3 = 10-17 DIM. 


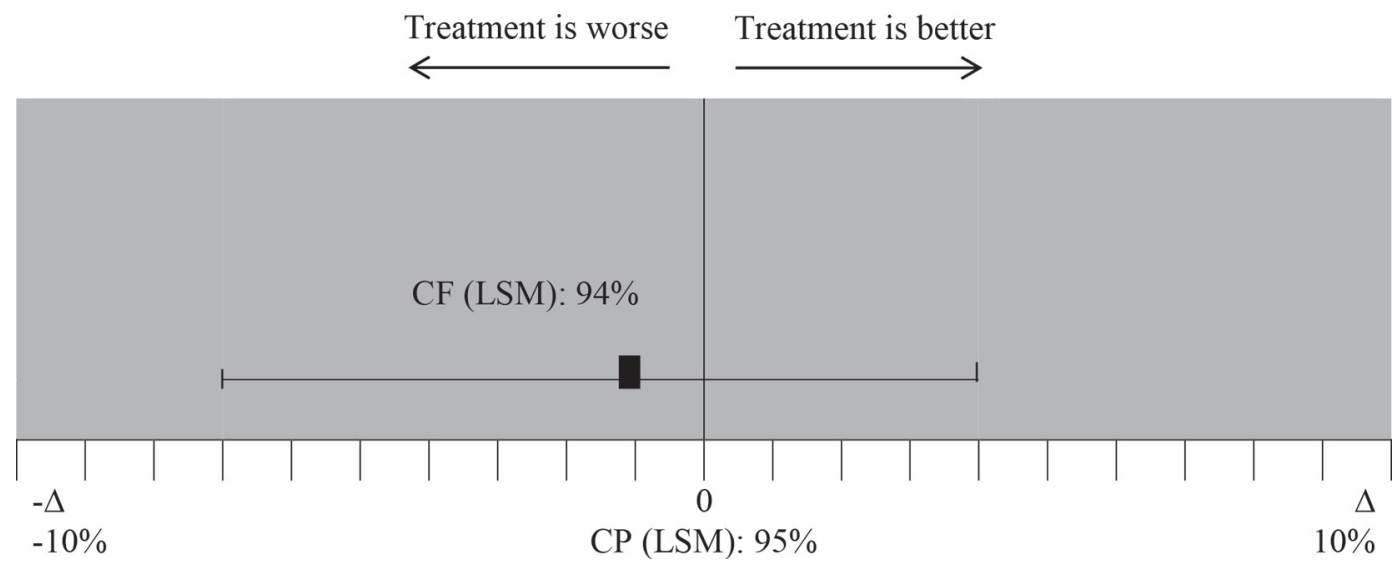

Figure 1. Noninferiority analysis of risk for cure for quarters from cows treated with Cefovet (CF; 250 mg of cephazoline; Merial Italia SPA, Milan, Italy; LSM $=94 \%, 95 \%$ CI: 87 to 97) compared with cows treated with Cepravin (CP; 250 mg of cephalonium dihydrate MSD Animal Health Srl, Segrate, Italy; LSM = 95\%, 95\% CI: 89 to $98 \%$ ). The error bars indicate 2 -sided $95 \%$ confidence intervals and the shaded area indicates the zone of noninferiority. Delta $(\Delta)$ represents the margin of noninferiority, preestablished at $10 \%$.

events within 60 DIM were compared between the 2 commercial products. It is important to note that all cows in this study received an internal teat sealant in addition to the DCT and studies have shown that the use of internal teat sealants has been associated with decreased risk of NIMI (Huxley et al., 2002; Godden et al., 2003). Given the current study design the effect of the teat sealant cannot be evaluated independently from the DCT.

This is the first prospective multiregion, multiherd randomized noninferiority study performed in Italy. It is difficult to compare results from this study to previous research because no such study has been performed in Italy. Additionally, although several noninferiority trials have evaluated DCT, no noninferiority studies have been performed comparing CF and CP. McDougall (2010) compared 2 cephalonium products (Cefamaster, Merial, Manukau City, Auckland, versus Cepravin Dry-cow, Intervet Schering-Plough, Upper Hutt) and included a negative control in New Zealand. Although one of the products (Cepravin) is similar to the product used in our study, the regional differences and negative control in McDougall (2010) do not allow for a direct comparison. Shephard et al. (2004) compared cephalonium and cloxacillin DCT in Australian dairy cows. However, our study compared a different set of drugs and their herd and cow selection focused on high SCC and high mastitis risk. Bradley et al. (2010) evaluated

Table 5. Crude quarter-level bacteriological cure $^{1}$ by treatment ${ }^{2}$

\begin{tabular}{|c|c|c|c|c|c|}
\hline \multirow[b]{2}{*}{ Bacteria } & \multicolumn{3}{|c|}{$\mathrm{S}^{3}$} & \multicolumn{2}{|c|}{$\%$ Cure } \\
\hline & $\mathrm{CF}$ & $\mathrm{CP}$ & Total & $\mathrm{CF}$ & $\mathrm{CP}$ \\
\hline $\mathrm{CNS}$ & 112 & 108 & 220 & 82 & 89 \\
\hline Staphylococcus aureus & 6 & 3 & 9 & 100 & 100 \\
\hline Streptococcus dysgalactiae & 3 & 7 & 10 & 100 & 100 \\
\hline Streptococcus uberis & 12 & 11 & 23 & 100 & 91 \\
\hline Streptococcus spp. & 14 & 6 & 20 & 100 & 100 \\
\hline Enterococcus faecalis & 5 & 2 & 7 & 100 & 100 \\
\hline Bacillus spp. & 2 & 3 & 5 & 100 & 100 \\
\hline Corynebacterium spp. & 9 & 7 & 16 & 100 & 100 \\
\hline Escherichia coli & 16 & 12 & 28 & 100 & 100 \\
\hline Enterobacter spp. & 2 & 1 & 3 & 100 & 100 \\
\hline Serratia spp. & 0 & 3 & 3 & - & 0 \\
\hline Total quarters at risk for cure & 182 & 165 & 347 & & \\
\hline Quarters experiencing a cure [\% (no.)] & & & & $89(162)$ & $90(149)$ \\
\hline
\end{tabular}

${ }^{1}$ Cure was defined as the failure to culture pathogens originally present at the dry off sample in either postpartum samples (S2 $=2$ - 9 DIM; S3 $=10-17$ DIM).

${ }^{2}$ Treatment group: $\mathrm{CF}=$ Cefovet $(250 \mathrm{mg}$ of cephazoline; Merial Italia SpA, Milan, Italy) and CP $=$ Cepravin (250 mg of cephalonium dehydrate MSD Animal Health Srl, Segrate, Italy).

${ }^{3} \mathrm{~S} 1=$ sample at dry-off. 
Table 6. Final multivariable logistic regression model for the analysis of odds of experiencing a cure ${ }^{1}$ between $\mathrm{S} 1, \mathrm{~S} 2$, and $\mathrm{S} 3^{2}$

\begin{tabular}{lcccccc}
\hline & & & & \multicolumn{2}{c}{$95 \% \mathrm{CI}^{4}$} \\
Variable & Coefficient & $\mathrm{SE}$ & Odds ratio $^{3}$ & $\mathrm{LCL}$ & $\mathrm{UCL}$ & $P$-value \\
\hline $\begin{array}{l}\text { Intercept } \\
\begin{array}{l}\text { Treatment } \\
\mathrm{CF}\end{array}\end{array}$ & 2.7 & 0.9 & & & & \\
$\mathrm{CP}$ & $\begin{array}{c}-0.2 \\
\text { Teat score at } \mathrm{S} 1=1,2\end{array}$ & 0.4 & 0.8 & 0.4 & 1.8 & 0.6 \\
Teat score at $\mathrm{S} 1=3,4$ & $\begin{array}{c}-1.6 \\
\text { Referent }\end{array}$ & 0.8 & 0.2 & 0.05 & 0.9 & 0.04 \\
\hline
\end{tabular}

${ }^{1}$ Cure was defined as the failure to culture pathogens originally present at the dry-off (S1) sample in both postpartum samples (S1 and S2).

${ }^{2} \mathrm{~S} 1=$ dry-off, S2 $=2-9$ DIM, S3 = 10-17 DIM.

${ }^{3}$ Odds for cure of infection.

${ }^{4}$ Confidence intervals for the odds ratio: lower (LCL) and upper (UCL) confidence limits.

${ }^{5} \mathrm{CF}=$ Cefovet (250 mg of cephazoline; Merial Italia SpA, Milan, Italy), CP = Cepravin (250 mg of cephalonium dehydrate MSD Animal Health Srl, Segrate, Italy).

the use of a cephalonium product in combination with or without a teat sealant depending on the potential infection status of the quarter at dry off. Again, although this study has a product with similar formulation as one of the products in the current study, the study design and population limits direct comparisons. More recently, noninferiority trials of 3 (in North America; Arruda et al., 2013a,b) and 2 DCT (Johnson et al., 2016) were carried out; however, given the differences in drug formulations, comparisons are not feasible.
To our knowledge, no Italian study has compared a cephazoline-based DCT.

Regional differences can have a pronounced effect on treatment regimens (Bradley and Green, 2009). One of the major strengths of our study is that it was conducted in commercial herds from different regions of Italy, using different management strategies. However, it is important to note that some of these herds were larger than average herds in Italy, where the average size is 70 to 100 cows in northern Italy. The study herds were lo-

Table 7. Crude quarter-level NIMI ${ }^{1}$ between $\mathrm{S}^{2}$ and $\mathrm{S}^{2}$ by treatment group ${ }^{3}$

\begin{tabular}{|c|c|c|c|}
\hline \multirow[b]{2}{*}{ Item } & \multicolumn{3}{|c|}{ Culture results at $\mathrm{S} 2$} \\
\hline & $\mathrm{CF}$ & $\mathrm{CP}$ & Total \\
\hline \multicolumn{4}{|l|}{ Gram-positive } \\
\hline CNS & 55 & 36 & 91 \\
\hline Staphylococcus aureus & 1 & 3 & 4 \\
\hline Streptococcus dysgalactiae & 2 & 3 & 5 \\
\hline Streptococcus uberis & 5 & 4 & 9 \\
\hline Streptococcus spp. & 2 & 5 & 7 \\
\hline Enterococcus faecalis & 5 & 0 & 5 \\
\hline Bacillus spp. & 3 & 2 & 5 \\
\hline Corynebacterium spp. & 0 & 0 & 0 \\
\hline Total gram-positive $\left[\right.$ no. $\left.(\%)^{4}\right]$ & $73(78)$ & $53(81)$ & $126(80)$ \\
\hline \multicolumn{4}{|l|}{ Gram-negative } \\
\hline Escherichia coli & 8 & 8 & 16 \\
\hline Enterobacter spp. & 0 & 0 & 0 \\
\hline Klebsiella spp. & 2 & 0 & 2 \\
\hline Serratia spp. & 4 & 2 & 6 \\
\hline Other gram-negative & 1 & 0 & 1 \\
\hline Total gram-negative $\left[\right.$ no. $\left.(\%)^{4}\right]$ & $13(14)$ & $10(15)$ & $23(14)$ \\
\hline Yeast & 6 & 3 & 9 \\
\hline Total cultures with growth at S2 & 94 & 66 & 160 \\
\hline \multicolumn{4}{|c|}{$\begin{array}{l}{ }^{1} \text { New IMI defined as no significant growth at } \mathrm{S} 1 \text { and a pathogen at S2, or a different pathogen at S2 } \\
\text { compared with S1. } \\
{ }^{2} \mathrm{~S} 1=\text { dry-off, S2 }=2-9 \text { DIM. } \\
{ }^{3} \mathrm{CF}=\text { Cefoyet }(250 \text { of }\end{array}$} \\
\hline
\end{tabular}


Table 8. Final multivariable logistic regression model for the analysis of odds of experiencing a new IMI between S1 and S2 ${ }^{1}$

\begin{tabular}{|c|c|c|c|c|c|c|}
\hline Variable & Coefficient & $\mathrm{SE}$ & Odds ratio $^{2}$ & \multicolumn{2}{|c|}{$95 \% \mathrm{CI}^{3}$} & $P$-value \\
\hline Intercept & -3.7 & 0.3 & & & & \\
\hline $\mathrm{CF}$ & 0.3 & 0.2 & 1.3 & 0.9 & 1.9 & 0.2 \\
\hline $\begin{array}{l}\text { Length of dry period } \geq 60 \mathrm{~d} \\
\text { Length of dry period }<60 \mathrm{~d}\end{array}$ & $\begin{array}{c}\text { Referent } \\
0.005 \\
\text { Referent }\end{array}$ & 0.003 & 1.0 & 0.9 & 1.0 & 0.09 \\
\hline $\begin{array}{l}\text { Hygiene score at } \mathrm{S} 2=1,2 \\
\text { Hygiene score at } \mathrm{S} 2=3,4\end{array}$ & $\begin{array}{c}0.5 \\
\text { Referent }\end{array}$ & 0.2 & 1.7 & 1.1 & 2.6 & 0.02 \\
\hline
\end{tabular}

${ }^{1} \mathrm{~S} 1=$ dry-off, $\mathrm{S} 2=2-9$ DIM.

${ }^{2}$ Odds for cure of infection.

${ }^{3}$ Confidence intervals for the odds ratio: lower (LCL) and upper (UCL) confidence limits.

${ }^{4} \mathrm{CF}=$ Cefovet $(250 \mathrm{mg}$ of cephazoline; Merial Italia SpA, Milan, Italy), CP = Cepravin (250 mg of cephalonium dehydrate MSD Animal Health Srl, Segrate, Italy).

cated in Lombardia, where at least $50 \%$ of dairy herds are located. This area produces about $42 \%$ of all milk in Italy. Additionally, although season has been shown to have an effect on the risk of mastitis (Oltenacu and Ekesbo, 1994; Olde Riekerink et al., 2007), most of the cows in our study calved during the summer months (May-September); thus, season was not included in the model.

\section{IMI Status at Dry Off and Prevalence of IMI Postcalving}

The crude prevalence of infection at dry off in this study $(15.3 \%)$ was slightly lower than North American studies, but within the range $(12.8-38.9 \%)$ of previous reports in North American studies (Godden et al., 2003; Pantoja et al., 2009; Arruda et al., 2013b); however, it is well below the range reported by Bradley et al. (2015) in a study evaluating IMI in the dry period in several European countries. In the Bradley et al. (2015) study, the prevalence of IMI at dry off was $56 \%$, with the majority of the growth due to Cornybacterium spp. $(37.8 \%)$, followed by CNS (19.5\%). Some difference in prevalence of infection may be due to differences in IMI definitions and sampling methodology among studies. Godden et al. (2003), for example, defined an IMI infection as the presence of 1 colony in $10 \mu \mathrm{L}$ for any pathogen, whereas Pantoja et al. (2009) reported a $12.8 \%$ prevalence, but the threshold for a new IMI was 3 or more colonies in the same amount of milk.

The IMI prevalence postcalving can be variable and can range from 6.9 to $40.4 \%$ (Hallberg et al., 2006; Pantoja et al., 2009). This high variability is likely due to differences in population [e.g., Hallberg et al. (2006) enrolled only high-SCC cows]. The postcalving preva- lence of IMI in the present at S2 was 7.8\%, which is still within the range of previous studies.

Similar to previous dry cow North American mastitis studies (Godden et al., 2003; Arruda et. al., 2013a), the pathogen most commonly isolated was CNS. The next most common pathogens isolated were E. coli and Strep. dysgalactiae, both in much smaller numbers than CNS. Similarly to the Arruda et al. (2013a) study, Bacillus spp. were found at all culture time points. Although the role of Bacillus spp. is not well understood, and may not be reported regularly, it has been shown to be the cause of CM (Nieminen et al., 2007). In our study,

Table 9. Crude culture results of clinical mastitis within 60 DIM by treatment group $^{1}$ (no., $\%$ in parentheses)

\begin{tabular}{|c|c|c|c|}
\hline \multirow[b]{2}{*}{ Bacteria } & \multicolumn{2}{|c|}{ Treatment group } & \multirow[b]{2}{*}{ Total } \\
\hline & $\mathrm{CF}$ & $\mathrm{CP}$ & \\
\hline Bacillus spp. & $1(3)$ & $1(2)$ & $2(2.5$ \\
\hline CNS & $1(3)$ & $6(14)$ & $7(9)$ \\
\hline Escherichia coli & $4(11)$ & $10(24)$ & $14(18)$ \\
\hline Enterococcus faecalis & $1(3)$ & $0(0)$ & $1(1)$ \\
\hline Klebsiella spp. & $0(0)$ & $2(5)$ & $2(3)$ \\
\hline No significant growth & $9(25)$ & $9(21)$ & $18(23)$ \\
\hline Pasteurella multocida & $0(0)$ & $1(2)$ & $1(1)$ \\
\hline Prototheca zopfii & $0(0)$ & $1(2)$ & $1(1)$ \\
\hline Pseudomonas spp. & $1(3)$ & $0(0)$ & $1(1)$ \\
\hline Streptococcus dysgalactiae & $1(3)$ & $1(2)$ & $2(3)$ \\
\hline Streptococcus uberis & $5(14)$ & $5(12)$ & $10(13)$ \\
\hline Streptococcus spp. & $1(3)$ & $0(0)$ & $1(1)$ \\
\hline Missing culture information ${ }^{2}$ & $12(33)$ & $6(14)$ & $18(23)$ \\
\hline Total & 36 & 42 & 78 \\
\hline
\end{tabular}

${ }^{1} \mathrm{CF}=$ Cefovet $(250 \mathrm{mg}$ of cephazoline; Merial Italia SPA, Milan, Italy); $\mathrm{CP}=$ Cepravin $(250 \mathrm{mg}$ of cephalonium dehydrate MSD Animal Health Srl, Segrate, Italy).

${ }^{2}$ Animals had a positive mastitis event, but no culture information was available. 
Table 10. Final Cox proportional hazards regression model for the analysis of effect of treatment on risk for experiencing a clinical mastitis event between calving and 60 DIM

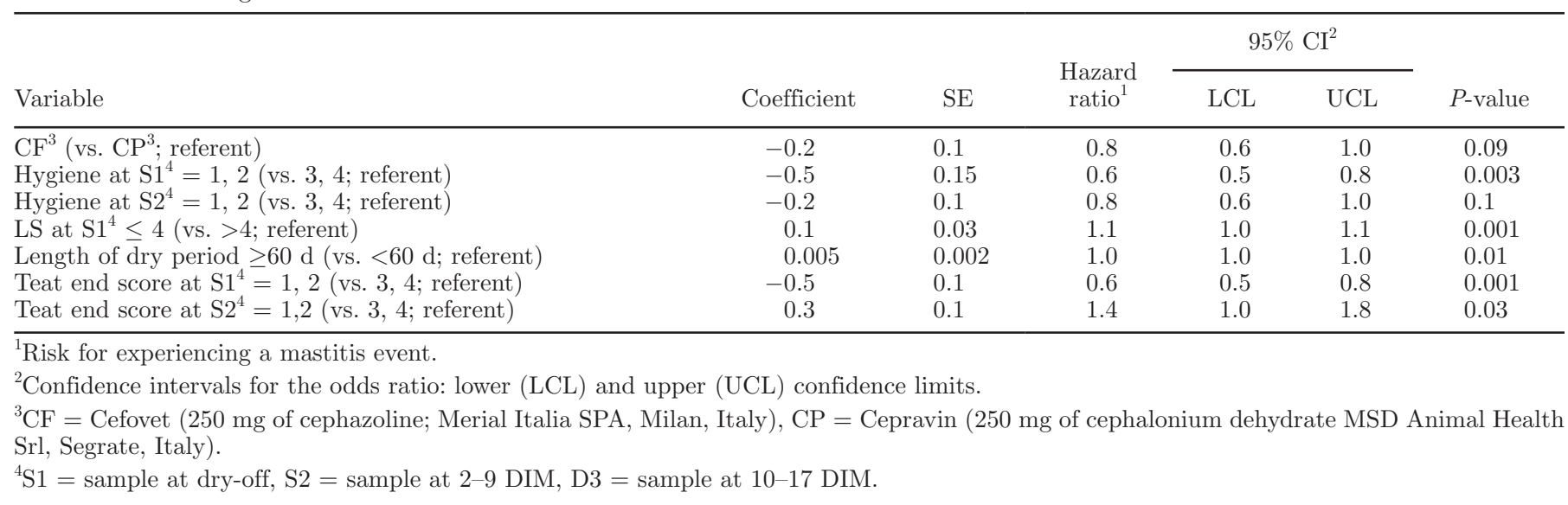

we found only 2 cases of CM where Bacillus spp. were cultured in the milk sample.

\section{IMI Prevalence and Power Calculations}

It is important to discuss that the crude number of IMI at dry off was lower (15\%) than the assumed $(30 \%)$ when the sample size was calculated. Post hoc sample size calculations were performed using statistical software (noninferiority test of 2 proportions; PASS 2014, V.14.05, NCSS LLC, Kaysville, UT) and showed that only 198 quarters were needed to have $80 \%$ power with the prestated $10 \%$ difference between groups. Post hoc power calculations were done with the new smaller sample size (165) and previously defined terms and was $73 \%$. Although we noted a loss of power due to the smaller $\mathrm{N}$, we do not consider this a weakness in the study given that the numeric difference observed in cure risk was very small (observed delta $=0.01$ ). Therefore, we do not believe that the loss of power in any way compromised the validity of the conclusions reached in this study.

\section{Effect of Treatment on Odds of Cure Between S1, S2, and S3}

A cure was defined as a negative culture at both $\mathrm{S} 2$ and $\mathrm{S} 3$ or different pathogen at those time points when compared with S1. These results were evaluated in parallel (a positive culture in either sample was a classified as a positive test result, i.e., failure of cure) to increase the sensitivity of the test. The current study found that $\mathrm{CF}$ was noninferior to $\mathrm{CP}$ on the risk of experiencing a cure of an IMI during the dry period. The crude proportion of quarters experiencing a cure in this study was approximately $90 \%$ and this is similar to North American studies (Arruda et. al., 2013a; Johnson et al.,
2016). It is important to note that although there was numerical difference $(1 \%)$ in the proportion cured at the crude level (89 and 90\% in CF and CP groups, respectively), this difference was well within the a priori set of $10 \%$. Additionally, further analysis controlling for potential confounders showed a similar numerical difference $(1 \%)$ between the 2 groups and overlapping 95\% confidence interval. Similar to previous reports (Godden et al., 2003; Arruda et al., 2013a) of DCT, a difference was noted based on teat-end scores at dry off; however, contrary to these reports where lower teat-end scores were associated with higher odds of a cure, in the current study the reverse relationship was seen. Data has shown that teat ends with mild to moderate rings versus no rings or rough rings have a reduced risk of CM (Neijenhuis et al., 2000), and similar results were seen when subclinical mastitis was evaluated in both herds in the United Kingdom and in the United States (Sieber and Farnsworth, 1981; Lewis et al., 2000). This may be due to the fact that a small amount of keratinization (mild to moderate rings) is normal and may represent a protective response of the tissue to milking pressures, but also allows for proper teat-end closure. Although the odds of a cure and not new infections was the outcome of interest in this part of the study, it is reasonable to hypothesize that an appropriate response to milking pressures and proper closing of the teat end are also important for a cow to overcome an infection, hence a cure.

\section{Effect of Treatment on Odds of a NIMI at S2}

The current study found no effect of treatment on odds for presence of a NIMI at S2. Similar to previous reports (Arruda et al., 2013a; Johnson et al., 2016) a NIMI was defined as a new pathogen in the first week postpartum (S2) when compared with a negative 
culture result or different pathogen at dry off (S1). Additionally, it was hypothesized that a positive culture result at S2 may not be associated with the effects of the DCT, but rather the cow's environment postpartum; the resulting increase in false positives of NIMI thus resulted in a decrease in specificity of this test as it relates to the effect of DCT. Similar to other reports, the most common pathogen isolated from samples which showed any growth was CNS, and the second most commonly isolated NIMI pathogen at S2 was $E$. coli (Godden et al., 2003; Pantoja et al., 2009; Arruda et. al., 2013a; Johnson et al., 2016).

In the model evaluating the odds of a NIMI length of dry period had a small biological difference between the 2 groups (odds ratio $=1.0$ ) and a $9 \%$ chance that this difference was due to chance; thus, although it was included in the final model, it does not have a significant effect on the outcome. However, quarters with teat-end scores (1 and 2) at S1 versus those with 3 and 4 had significant lower odds (odds ratio $=0.6$ ) of a NIMI. Interestingly, cows with lower hygiene scores had higher odds (odds ratio $=1.6$ ) of developing a NIMI. This could be due to the fact that hygiene score is a cowlevel parameter and this evaluation is being done at the quarter level. Although we found a statistically and biologically significant effect, the cow-level measurement may not reflect the quarter-level environment.

\section{Infections Within 60 DIM}

The crude incidence of $\mathrm{CM}$ was $13.6 \%$ at the cow level, which is approximately $3.4 \%$ at the quarter level. This is within the range reported by North American studies, which report 3 to $6 \%$ (Godden et al., 2003; Arruda et al., 2013a). The results of the cultures are similar to other studies, where no growth was the most likely outcome, followed by E. coli. (Johnson et al., 2016).

When the model was evaluated, lower teat-end scores at S2 were associated with higher risk of CM. Although it is expected that rougher teat ends would be associated with higher risk of CM, it is important to remember the potential interactions between teat-end scores and other factors; for example, the shape of the teat, udder depth, and inverted teat ends can affect the risk (Neijenhuis et al., 2000). Additionally, the risk of $\mathrm{CM}$ due to teat-end scores increases as DIM increases; specifically, at 2 to $5 \mathrm{mo}$ in lactation (Neijenhuis et al., 2001) in the current study the cows were only followed to 60 DIM, thus there may not have been enough time to see the difference in risk. Lower hygiene scores at S1 and S2 and teat-end scores at S1 were associated with a decreased risk of CM. Although the length of dry period was statistically significant, the small hazard ratio
(1.0) results in trivial difference between groups. Last, although we found no statistical significant difference ( $P=0.09)$ between treatment on the risk for developing $\mathrm{CM}$, there was a numerical difference between the treatment groups ( $46 \%$ in $\mathrm{CF}$ vs. $54 \% \mathrm{CP}$ ), and the hazard ratio (0.8) can be interpreted as a decreased risk of $\mathrm{CM}$ with the use of $\mathrm{CF}$ versus $\mathrm{CP}$.

\section{CONCLUSIONS}

Results from this randomized noninferiority study demonstrated that, in herds using a blanket internal teat sealant infusion at dry off, no difference existed between $\mathrm{CF}$ and $\mathrm{CP}$ regarding the cure risk for an existing infection at dry off, odds of developing a new infection at 2 to $9 \mathrm{DIM}$, or risk of $\mathrm{CM}$ event within 60 DIM. When choosing between the 2 tested dry cow antimicrobials for blanket dry cow therapy in conjunction with an internal teat sealant, factors other than cure risk of existing infections, odds of a new infection, or risk of CM can be used. Examples of such factors include cost of the product, ease of administration, recommended dry period length, and milk and meat withholding times related to antibiotic residue risk.

\section{ACKNOWLEDGMENTS}

The authors acknowledge Merial Italia SpA for financial support and also the farm owners and staff for help.

\section{REFERENCES}

Arruda, A. G., S. Godden, P. Rapnicki, P. Gorden, L. Timms, S. S. Aly, T. W. Lehenbauer, and J. Champagne. 2013a. Randomized noninferiority clinical trial evaluating 3 commercial dry cow mastitis preparations: I. Quarter-level outcomes. J. Dairy Sci. 96:4419-4435.

Arruda, A. G., S. Godden, P. Rapnicki, P. Gorden, L. Timms, S. S. Aly, T. T. W. Lehenbauer, and J. Champagne. 2013b. Randomized noninferiority clinical trial evaluating 3 commercial dry cow mastitis preparations: II. Cow health and performance in early lactation. J. Dairy Sci. 96:6390-6399.

Blackwelder, W. C., and M. A. Chang. 1984. Sample size graphs for proving the null hypothesis. Control. Clin. Trials 5:97-105.

Bradley, A. J., J. E. Breen, B. Payne, P. Williams, and M. J. Green. 2010. The use of a cephalonium containing dry cow therapy and internal teat sealant, both alone and in combination. J. Dairy Sci. 93:1566-1577.

Bradley, A. J., S. De Vliegher, M. J. Green, P. Larrosa, B. Payne, E. S. van de Leemput, O. Samson, D. Valckenier, T. Van Werven, H. W. Waldeck, V. White, and L. Goby. 2015. An investigation of the dynamics of intramammary infections acquired during the dry period on European dairy farms. J. Dairy Sci. 98:6029-6047.

Bradley, A. J., and M. J. Green. 2000. A study of the incidence and significance of intramammary enterobacterial infections acquired during the dry period. J. Dairy Sci. 83:1957-1965.

Bradley, A. J., and M. J. Green. 2009. Factors affecting cure when treating bovine clinical mastitis with cephalosporin-based intramammary preparations. J. Dairy Sci. 92:1941-1953. 
Dann, R. S., and G. G. Koch. 2008. Methods for one-sided testing of the difference between proportions and sample size considerations related to non-inferiority clinical trials. Pharm. Stat. 7:130-141.

Dohoo, I. R., J. Smith, S. Andersen, D. F. Kelton, S. Godden, and Mastitis Research Workers' Conference. 2011. Diagnosing intramammary infections: Evaluation of definitions based on a single milk sample. J. Dairy Sci. 94:250-261.

Falkenberg, U., B. Tenhagen, B. Baumgartner, and W. Heuwieser. 2003. Relationship between teat duct characteristics and prevalence of intramammary infections with S. agalactiae in dairy cows. Pages 300-301 in Proc. Natl. Mastitis Counc. Mtg., Fort Worth, TX. Natl. Mastitis Council Inc., Madison, WI.

Farrington, C. P., and G. Manning. 1990. Test statistics and sample size formulae for comparative binomial trials with null hypothesis of non-zero risk difference or non-unity relative risk. Stat. Med. 9:1447-1454

Ferguson, J. D., D. T. Galligan, and N. Thomsen. 1994. Principal descriptors of body condition score in Holstein cows. J. Dairy Sci. 77:2695-2703.

Godden, S., P. Rapnicki, S. Stewart, J. Fetrow, A. Johnson, R. Bey, and R. Farnsworth. 2003. Effectiveness of an internal teat seal in the prevention of new intramammary infections during the dry and early-lactation periods in dairy cows when used with a dry cow intramammary antibiotic. J. Dairy Sci. 86:3899-3911.

Green, M. J., L. E. Green, G. F. Medley, Y. H. Schukken, and A. J. Bradley. 2002. Influence of dry period bacterial intramammary infection on clinical mastitis in dairy cows. J. Dairy Sci. 85:25892599 .

Halasa, T., O. Osterås, H. Hogeveen, T. van Werven, and M. Nielen. 2009. Meta-analysis of dry cow management for dairy cattle. Part 1. Protection against new intramammary infections. J. Dairy Sci. 92:3134-3149.

Hallberg, J. W., M. Wachowski, W. M. Moseley, K. J. Dame, J. Meyer, and S. L. Wood. 2006. Efficacy of intramammary infusion of ceftiofur hydrochloride at drying off for treatment and prevention of bovine mastitis during the nonlactating period. Vet. Ther. 7:35-42.

Huxley, J. N., M. J. Green, L. E. Green, and A. J. Bradley. 2002. Evaluation of the efficacy of an internal teat sealer during the dry period. J. Dairy Sci. 85:551-561.

Johnson, A. P., S. M. Godden, E. Royster, S. Zuidhof, B. Miller, and J. Sorg. 2016. Randomized noninferiority study evaluating the efficacy of 2 commercial dry cow mastitis formulations. J. Dairy Sci. 99:593-607.

Lewis, S., P. Cockcroft, R. A. Bramley, and P. G. G. Jackson. 2000. The likelihood of subclinical mastitis in quarters with different types of teat lesions in dairy cows. Cattle Pract. 8:293-299.

McDougall, S. 2010. A randomised, non-inferiority trial of a new cephalonium dry-cow therapy. N. Z. Vet. J. 58:45-58.
Miettinen, O., and M. M. Nurminen. 1985. Comparative analysis of two rates. Stat. Med. 4:213-226.

Neijenhuis, F., H. W. Barkema, H. Hogeveen, and J. P. T. M. Noordhuizen. 2000. Classification and longitudinal examination of callused teat ends in dairy cows. J. Dairy Sci. 83:2795-2804

Neijenhuis, F., H. W. Barkema, H. Hogeveen, and J. P. T. M. Noordhuizen. 2001. Relationship between teat end callosity and occurrence of clinical mastitis. J. Dairy Sci. 84:2664-2672.

Nieminen, T., N. Rintaluoma, M. Andersson, A.-M. Taimisto, T. AliVehmas, A. Seppala, O. Priha, and M. Salkinoja-Salonen. 2007. Toxinogenic Bacillus pumilus and Bacillus licheniformis from mastitic milk. Vet. Microbiol. 124:329-339.

NMC (National Mastitis Council). 1999. Laboratory Handbook on Bovine Mastitis. NMC, Madison, WI.

Olde Riekerink, R. G., H. W. Barkema, and H. Stryhn. 2007. The effect of season on somatic cell count and the incidence of clinical mastitis. J. Dairy Sci. 90:1704-1715.

Oltenacu, P. A., and I. Ekesbo. 1994. Epidemiology study of clinical mastitis in dairy cattle. Vet. Res. 25:208-212

Pantoja, J. C. F., C. Hulland, and P. L. Ruegg. 2009. Dynamics of somatic cell counts and intramammary infections across the dry period. Prev. Vet. Med. 90:43-54

Scherpenzeel, C. G., I. E. den Uijl, G. van Schaik, R. G. Olde Riekerink, J. M. Keurentjes, and T. J. Lam. 2014. Evaluation of the use of dry cow antibiotics in low somatic cell count cows. J. Dairy Sci. 97:3606-3614.

Schreiner, D. A., and P. L. Ruegg. 2003. Relationship between udder and leg hygiene scores and subclinical mastitis. J. Dairy Sci. 86:3460-3465.

Schuirmann, D. J. 1999.Confidence interval methods for bioequivalence testing with binomial endpoints. Pages 227-232 in Proceedings of the Biopharmaceutical Section. American Statistical Association, Alexandria, VA

Shephard, R. W., S. Burman, and P. Marcun. 2004. A comparative field trial of cephalonium and cloxacillin for dry cow therapy for mastitis in Australian dairy cows. Aust. Vet J. 82:624-629.

Sieber, R. L., and R. J. Farnsworth. 1981. Prevalence of chronic teat end lesions and their relationship to intramammary infection in 22 herds of dairy cattle. J. Am. Vet. Med. Assoc. 178:1263-1267.

Smith, K. L., D. A. Todhunter, and P. S. Schoenberger. 1985. Environmental pathogens and intramammary infection during the dry period. J. Dairy Sci. 68:402-417.

Todhunter, D. A., K. L. Smith, and J. S. Hogan. 1995. Environmental streptococcal intramammary infections of the bovine mammary gland. J. Dairy Sci. 78:2366-2374.

Whist, A. C., O. Østerås, and L. Sølverød. 2006. Clinical mastitis in Norwegian herds after a combined selective dry-cow therapy and teat-dipping trial. J. Dairy Sci. 89:4649-4659. 